\section{Gardening Increases Vegetable Consumption in School-aged Children: A Meta-analytical Synthesis}

\author{
Gail A. Langellotto ${ }^{1}$ and Abha Gupta
}

ADDITIONAL INDEX WORDs. elementary school, middle school, childhood obesity prevention, SNAP-Ed, nutrition education, school garden, vote-counting, literature review

\begin{abstract}
Summary. Although a handful of published reports suggest that garden-based nutrition education programs are effective in increasing fruit and vegetable consumption, many of these studies have low statistical power because of small sample sizes and lack of long-term data. In this study, we used meta-analytical techniques to examine the efficacy of garden-based nutrition education programs for increasing children's nutrition knowledge, preference for fruit and vegetables, and/or consumption of fruit and vegetables. We confined our analysis to peerreviewed studies that examined programs that were delivered to children in the United States. We looked at the relative impacts of garden-based nutrition education programs, compared with experimental controls (i.e., no nutrition education) and nutrition education programs without a gardening component. We compared the results of our meta-analysis with those of a vote counting analysis to illustrate the importance of repeated studies and quantitative analysis. In our vote counting analysis, the majority of the outcomes were nonsignificant in the control and nutrition education groups, but positive and significant for the gardening group. Our quantitative analysis of the impacts of gardening education programs on children's nutrition knowledge, preference for fruit and vegetables, and/or consumption of fruit and vegetables was limited by the small number of studies that reported the full suite of descriptive statistics needed to conduct a meta-analysis. Nonetheless, one striking and robust result emerged: gardening increased vegetable consumption in children, whereas the impacts of nutrition education programs were marginal or nonsignificant. We suggest two nonmutually exclusive hypotheses to explain our results: gardening increases access to vegetables and gardening decreases children's reluctance to try new foods. Our results suggest that gardening should be an integral component of wellness programs and policies. A historical lack of funding has impeded both the broader adoption of school gardens and rigorous research on the social, behavioral, and academic impacts of gardening on children. Recently, however, there has been an increase in federal support for gardening and garden-based research projects-a trend that we hope will continue and grow.
\end{abstract}

$\mathrm{B}$ ehavioral and dietary lifestyles responsible for weight gain and obesity are often learned at an early age (Cooke, 2007). Children (particularly adolescents) who are overweight are more likely to be overweight or obese during adulthood (Dietz, 1998) and are at risk for a variety of physical and psychosocial complications during their lifetime (Ebbeling et al., 2002). Thus, it is troubling that the prevalence of obesity among children and adolescents in the United States has more than doubled between 1963-65 and 2007-08 (Ogden and Carroll, 2010).

Department of Horticulture, OR State University, 4017 Agriculture and Life Sciences Building, Corvallis, OR 97331

${ }^{1}$ Corresponding author.

E-mail: gail.langellotto@oregonstate.edu. activity in children. Specifically, children's willingness to taste vegetables (Morris et al., 2001), knowledge of nutrition (Morris et al., 2002), and preference for fruit and vegetables (Hermann et al., 2006; Lineberger and Zajicek, 2000) have been shown to be positively affected by gardenbased educational activities. These results highlight the potential importance of garden-based activities to support a comprehensive nutrition education program.

Recently, there has been resurgent interest in educational gardens, prompted in part by high-profile calls for a garden in every school (Pollan, 2008 ) to foster an "edible education." Although educators may support the use of school gardens to promote healthy eating (Graham and Zidenberg-Cherr, 2005), lack of resources impedes the broader integration of gardens into school activities (Graham et al., 2005).

To effectively promote healthy eating habits via the use of school gardens, it is important to develop a thorough understanding of the efficacy of garden-based nutrition education programs. Although a handful of individual studies suggest that garden-based, experiential education activities are effective vehicles for increasing fruit and vegetable consumption and promoting healthy food choices in young children, many studies suffer from low statistical power because of small sample sizes and lack of long-term data (RobinsonO'Brien et al., 2009). In addition, because there is a practical limit to the number of servings of fruit and vegetables a child can consume per day, researchers studying the impact of school gardens on changes in fruit and vegetable consumption must be able to detect behavioral outcomes that are small in magnitude. Detecting such small changes requires a high degree of statistical power, which is often beyond the capability of a single study.

Meta-analysis offers a solution to the dilemma of low statistical power in individual studies by synthesizing the results of multiple independent studies that test the same hypothesis (Gurevitch and Hedges, 1993). Specifically, meta-analysis increases statistical power and reduces type II errors and is thus especially useful for summarizing experiments with low 
sample sizes and/or weak treatment effects (Arnqvist and Wooster, 1995). An additional benefit of meta-analytical techniques is that they can quantify the magnitude of a treatment effect for individual studies included in the analysis, as well as calculate the overall magnitude and significance of the cumulative effect across all studies examined (Rosenberg et al., 2000).

We used meta-analytical techniques to test the hypotheses that, over time, participation in an educational garden program would increase students' knowledge of nutrition, increase students' preference for fruit and vegetables, and increase students' consumption of fruit and vegetables. Specifically, we tested the hypothesis that garden-based nutrition education programs have greater impact on measured outcomes (e.g., nutrition knowledge, fruit and vegetable preference, fruit and vegetable consumption) than traditional nutrition education programs.

To illustrate the importance of repeated studies and statistical power to answer these questions, we also present the results of a vote counting analysis. Vote counting synthesizes the results of multiple studies by counting the number of nonsignificant and significant outcomes for a particular question (i.e., do gardenbased nutrition education programs increase vegetable consumption in children?). Together, these methods allowed us to address the relative efficacy of garden-based vs. more traditional nutrition education programs for changing knowledge, attitudes, and behaviors that support healthy weight management.

\section{Materials and methods}

Literature REVIEW. We conducted a literature review by systematically searching Google Scholar (Google, Mountain View, CA) for various combinations of the words: intervention, fruit, vegetable, garden, nutrition, consumption, school, and youth. We excluded the significant body of gray literature that exists on these subjects, in the form of reports to funding agencies and working group articles, and concentrated our efforts on peer-reviewed publications. We repeated our search keywords in the PubMed (National Library of Medicine, Bethesda, MD) and Web of Knowledge (Thomson
Reuters, New York) databases, as well as in the American Society of Horticultural Science archives. When we found relevant peer-reviewed research studies or reviews (e.g., Delgado-Noguera et al., 2011; French and Stables, 2003; Robinson-O'Brien et al., 2009), we cross-referenced these articles for additional studies.

We confined our search to those studies that worked with children in kindergarten through grade 12, and that were conducted in the United States. To be included in our review, studies had to report at least one of five response variables: nutrition knowledge, preferences for fruit and/or vegetables, and/or consumption of fruit and/or vegetables.

The treatments within these studies were categorized according to the type of nutrition education program that served as the intervention: "control," "nutrition education," or "garden." Children in a "control" group were not exposed to any type of formal nutrition education program. Children in a "nutrition education" group participated in a nutrition education program that did not include a gardening component. Children in a "garden" group participated in a nutrition education program that also included a gardening component.

Given these restrictions, we assembled a data set of 20 studies that reported 66 observations (i.e., outcomes or results) for nutrition knowledge, fruit and vegetable preference, and/or fruit and vegetable consumption (Table 1). Even though we restricted our search to studies that were conducted from kindergarten through 12 th grade, we only found studies that were conducted with students in kindergarten through grade eight.

Description of studies. All of the 20 included studies were quasiexperimental, in which the researchers first recruited an educational site (e.g., school, Boys and Girls Club, community garden, etc.) rather than directly recruiting children from across all possible sites. These types of experimental designs are called "quasi-experimental" because they lack a key element of randomized experiments: the random assignment of subjects to a treatment category. Only after cooperating sites were identified were students recruited to take part in a study.

Although the majority of studies included a control group that did not participate in a nutrition education and/or gardening program, six studies (Heim et al., 2009; Hermann et al., 2006; Koch et al., 2006; Lineberger and Zajicek, 2000; Poston et al., 2005; Wright and Rowell, 2010) did not include a control.

The majority of the studies with a nutrition education program focused on increasing the consumption of healthy foods and/or decreasing the consumption of unhealthy foods. Increasing physical activity and/or decreasing sedentary activities were also included as an aspect of many of these programs. In the studies that had a garden treatment, gardening activities (e.g., planting, maintaining, harvesting) were integrated into a nutrition education program. Detailed descriptions of each study included in our analyses can be found in Table 1.

Vote-counting anAlysis. For the vote-counting analysis, we scored the significance (either positive or negative) or nonsignificance of each observation of a treatment category (e.g., control, nutrition education, and gardening) on a response variable (e.g., nutrition knowledge, preferences for fruit or vegetables, and consumption of fruit or vegetables). Some studies (e.g., Koch et al., 2006; O'Brien and Shoemaker, 2006) reported the effect of a treatment category on the combined preference for fruit and vegetables and/or combined consumption of fruit and vegetables. We included these as separate response categories from preference or consumption of just fruit or just vegetables.

For this analysis, observations within studies were recorded as significant when the probability value was less than or equal to 0.05 , regardless of the type I error rate set by the studies' authors. Specifically, we scored the significance of the difference between pretest and posttest scores. If baseline data were not reported, we noted the significance of the difference between a control and treatment group at the end of a study. In our vote counting analysis, we separately considered changes in response variables between pretest and posttest measures from differences in response variables between an intervention (e.g., nutrition education, gardening) and a control.

A significant positive response (+) was recorded when the value of 


\section{Reviews}

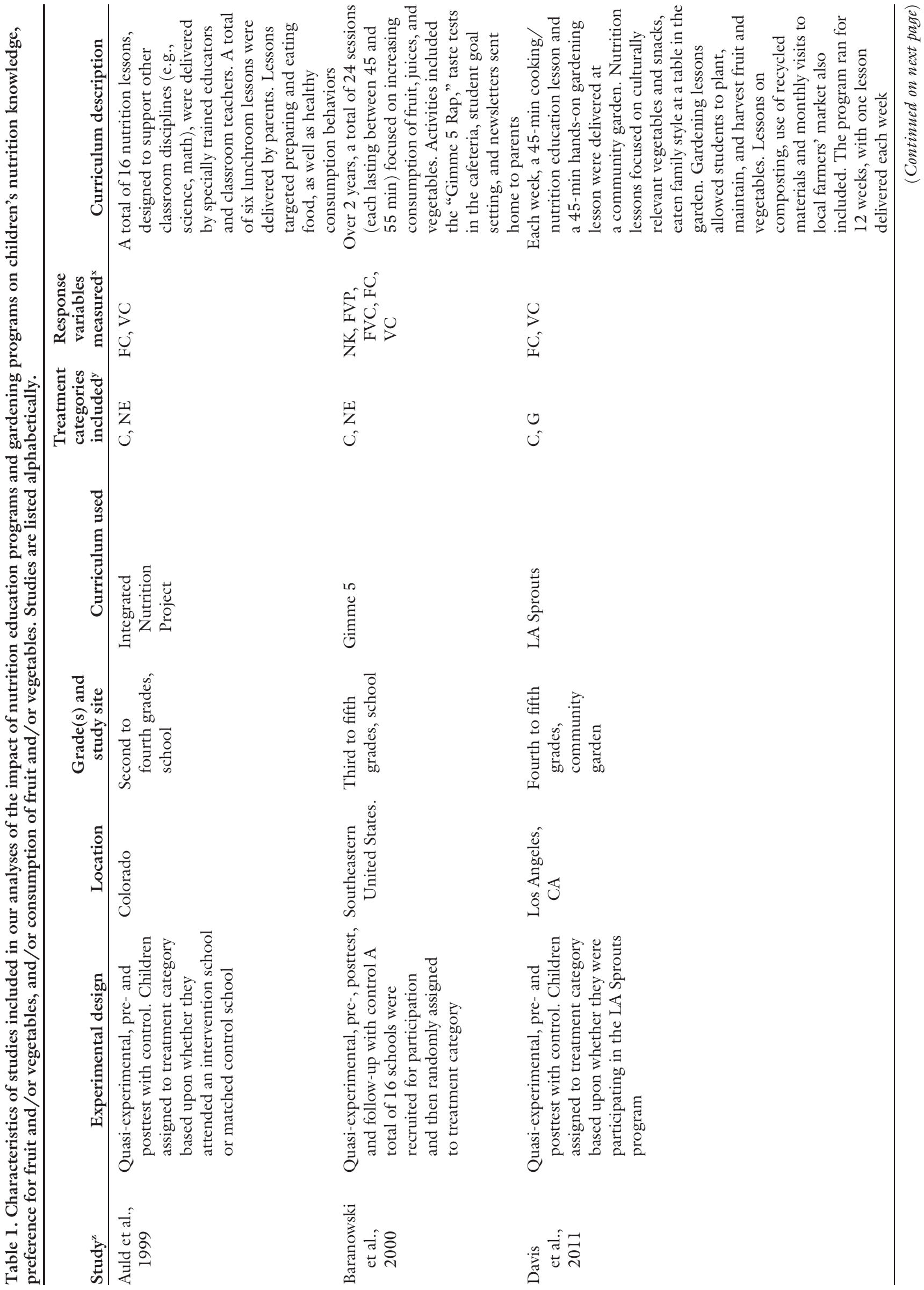




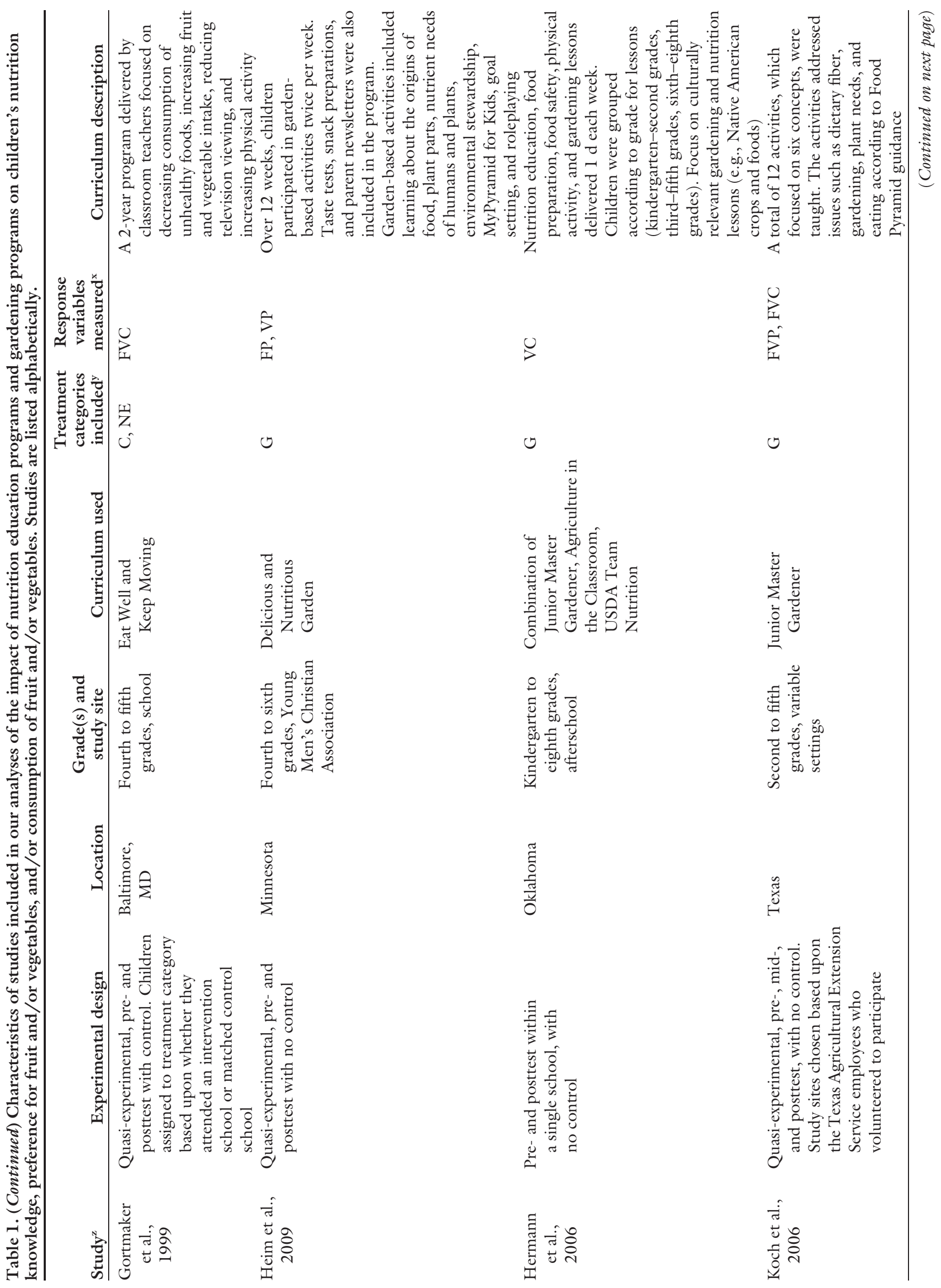

Hortlechnology · August 2012 22(4) 


\section{Reviews}

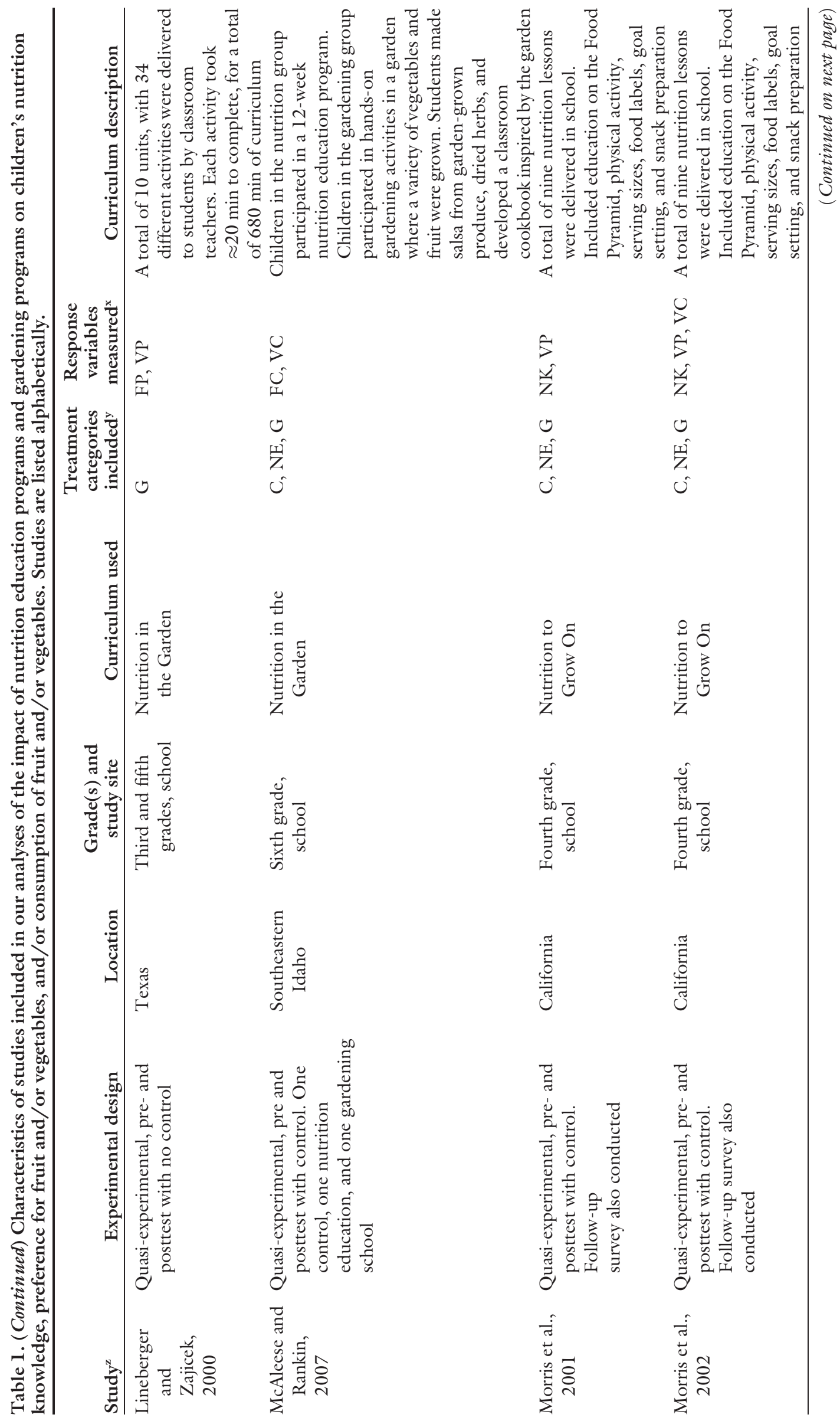




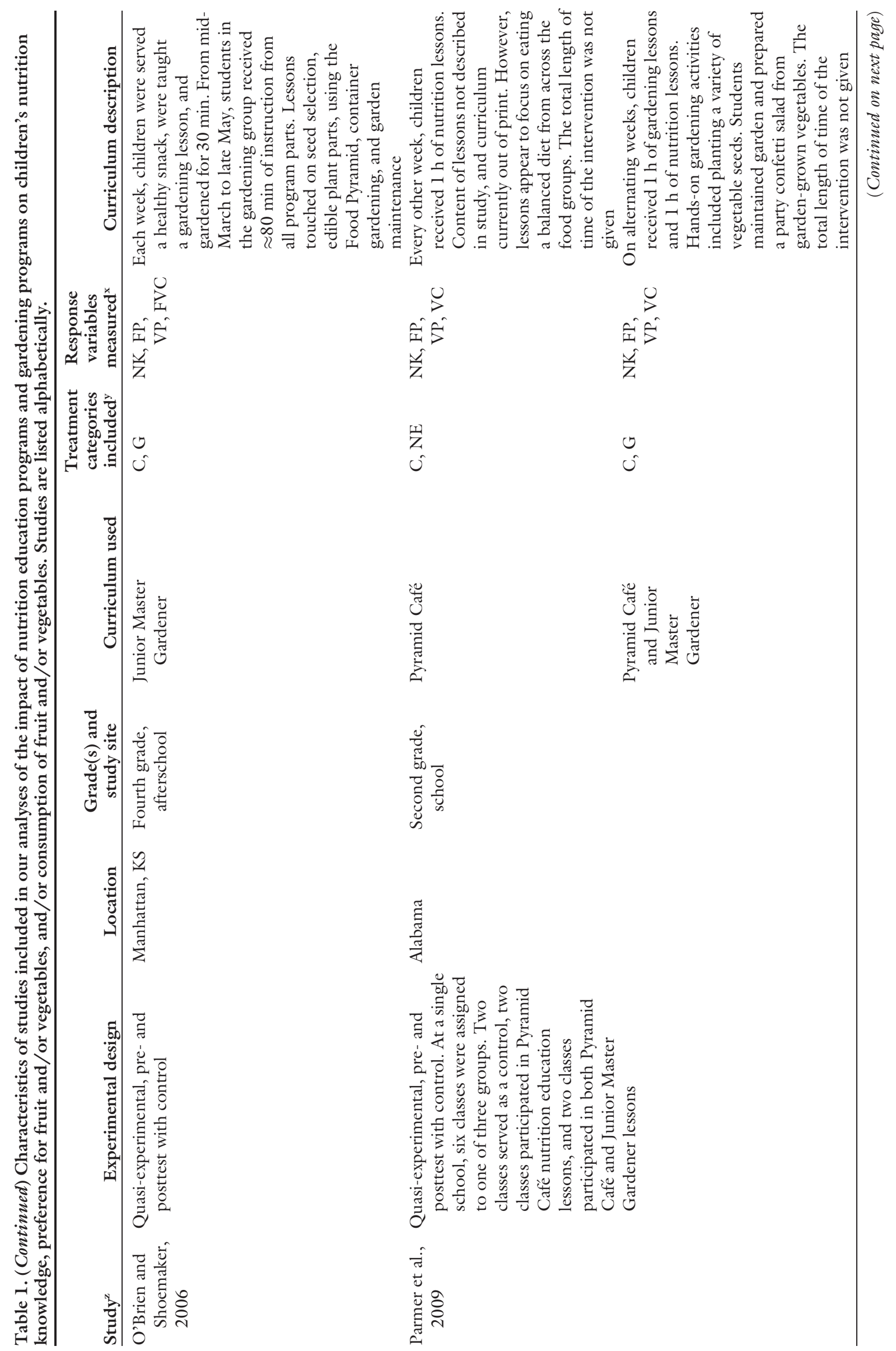




\section{Reviews}

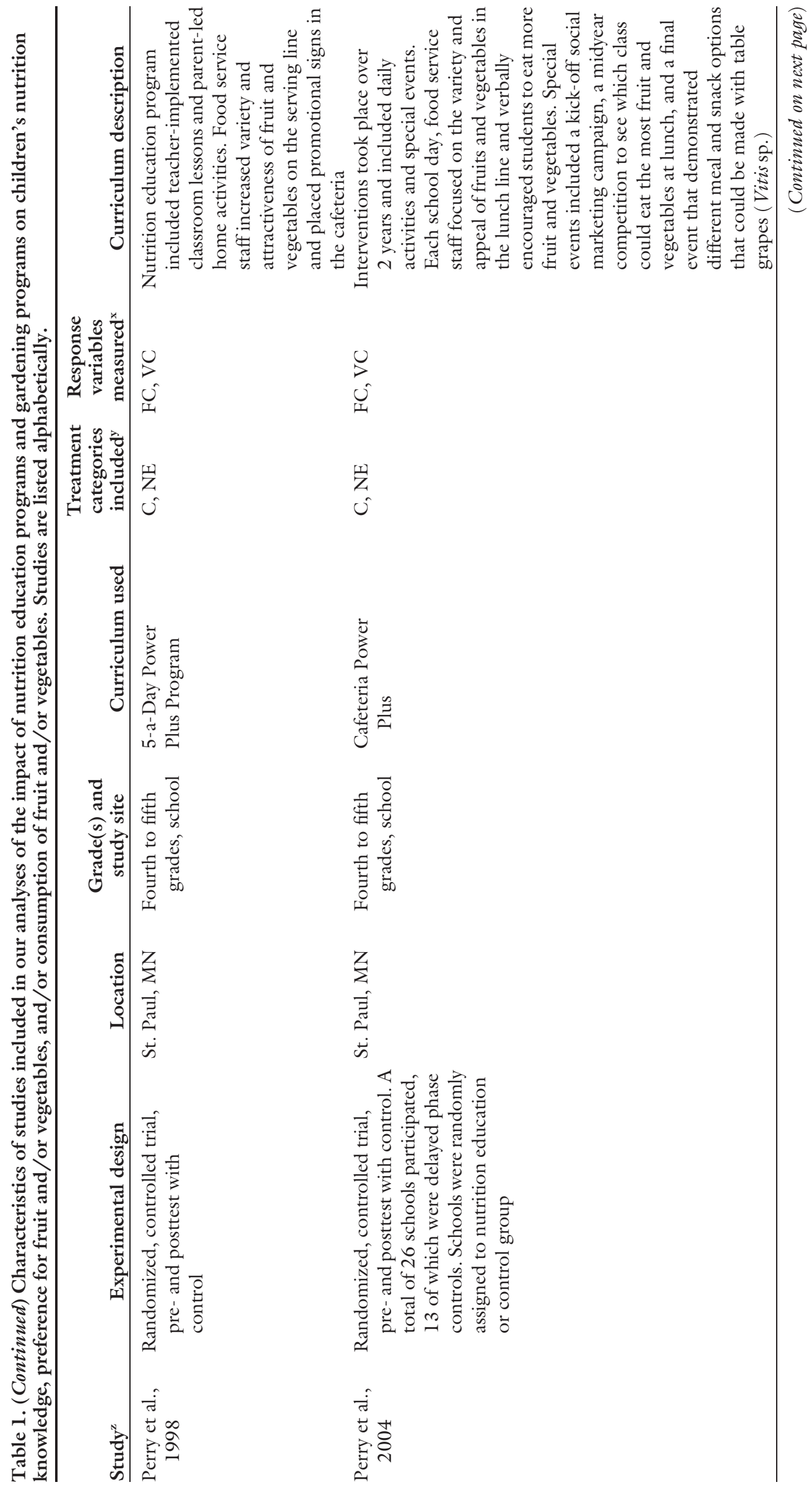




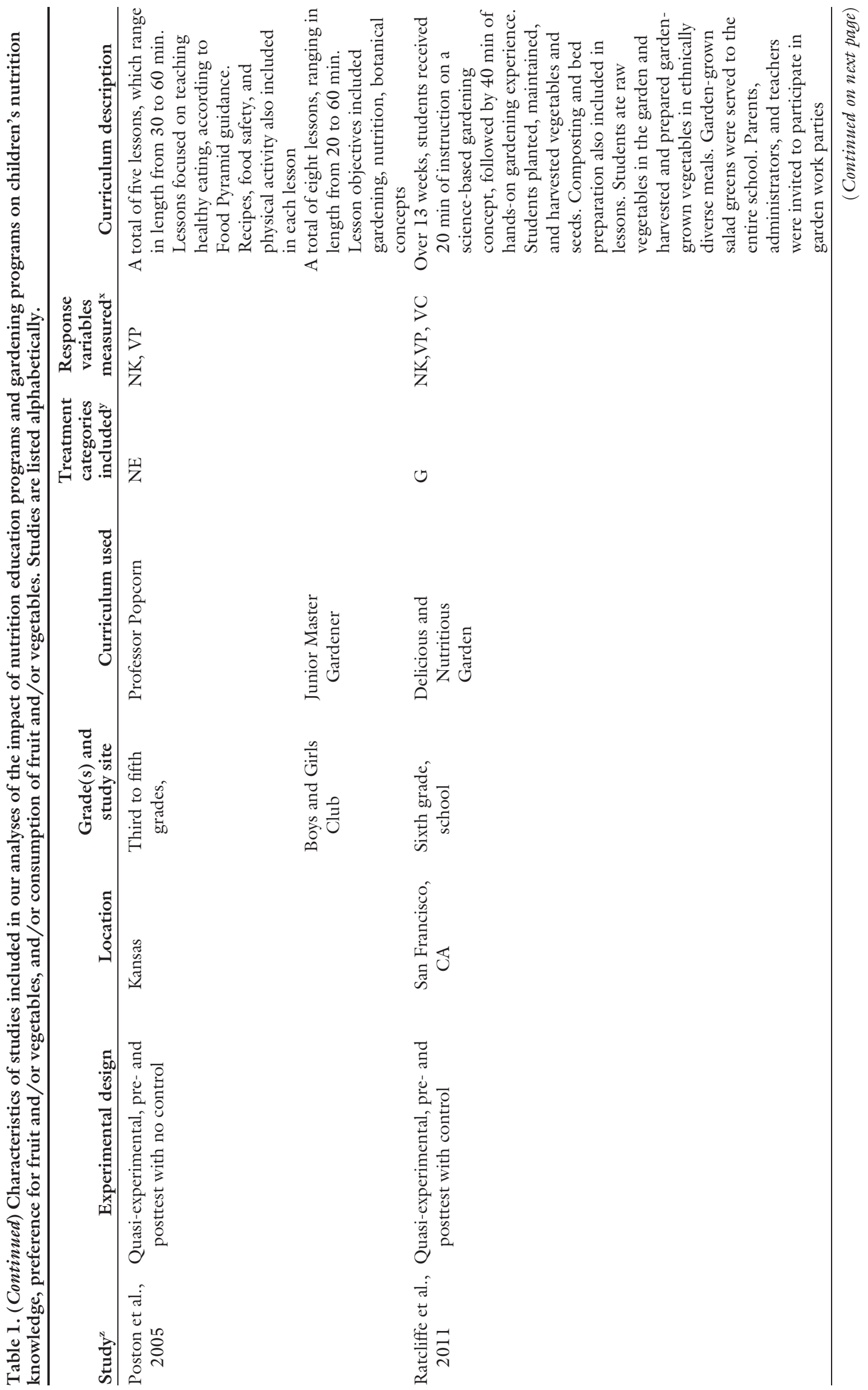




\section{Reviews}

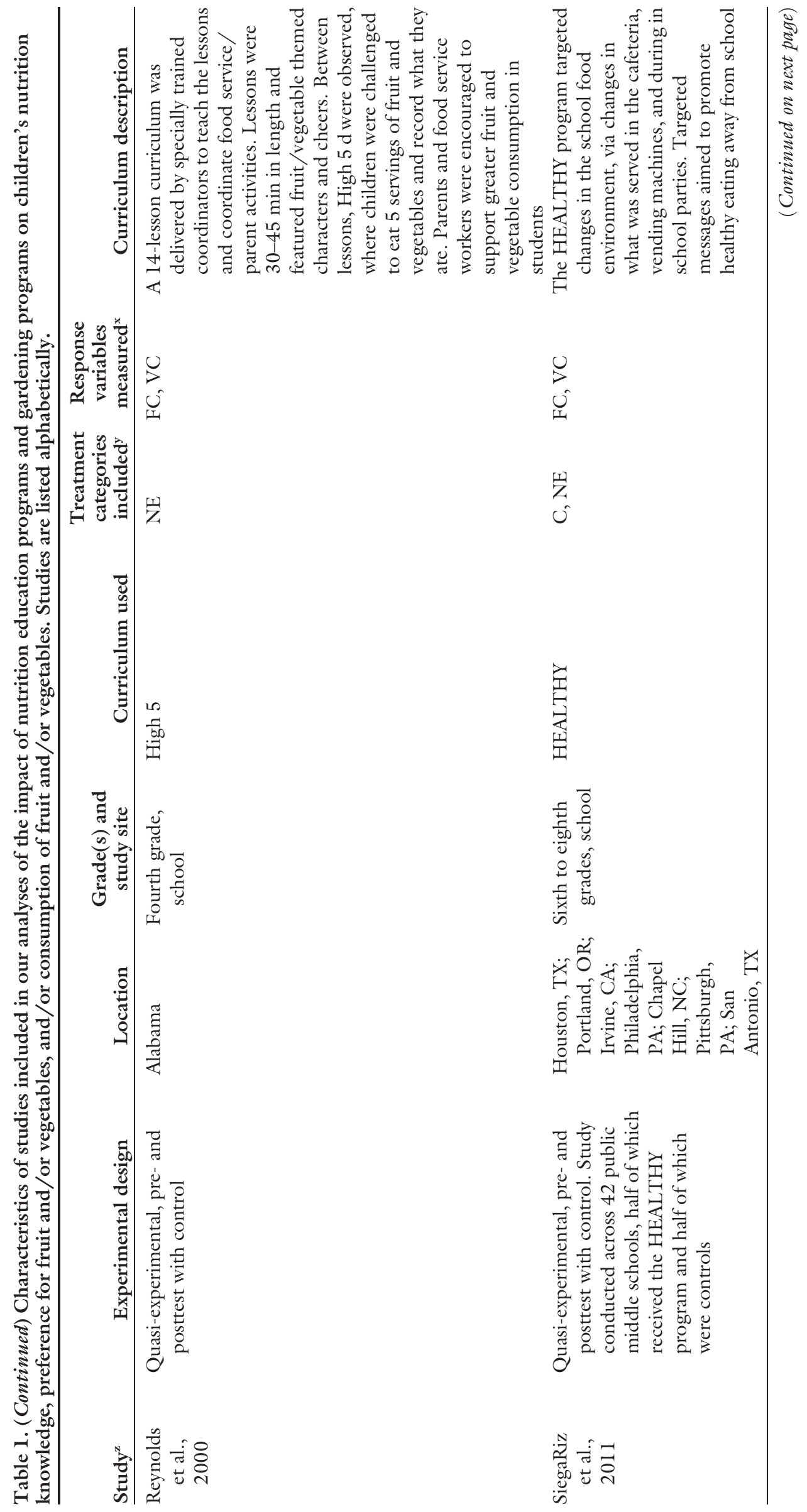




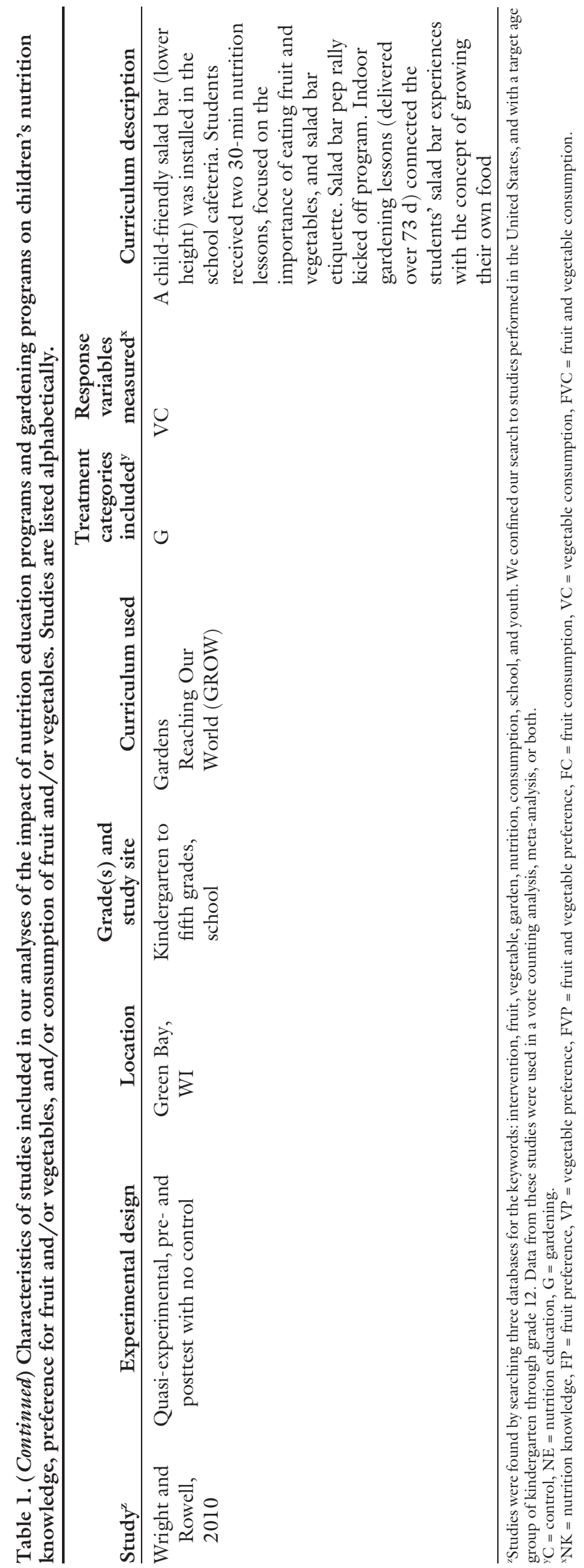

the posttest was significantly greater than the pre-test value or when the value of the treatment group was significantly greater than the control. A significant negative response (-) was recorded when the posttest value was significantly less than the pretest value or when the value of the treatment group was significantly less than the control. Nonsignificant differences $(\varnothing)$ were also noted. In one case (Baranowski et al., 2000), we qualitatively assessed the significance by examining reported least squared means and graphical data. In another case (Siega-Riz et al., 2011), we conducted a post hoc analysis of the reported data to determine the significance of the difference between pre- and posttest values, for both the control and the nutrition education treatment.

We counted up the total number of significant positive, negative, and null responses among studies that reported pre- and posttest data, as well as studies that reported differences between control groups and interventions. This allowed us to qualitatively analyze the relative effect of no education, nutrition education, and garden-based education on children's nutrition knowledge, preferences for fruit and/or vegetables, and consumption of fruit and/ or vegetables.

Meta-Analysis. We used metaanalytical techniques to quantitatively examine the changes in children's nutrition knowledge, preference for fruit and vegetables, and consumption of fruit and vegetables as a function of whether they participated in a nutrition education program or gardening program.

Meta-analytical techniques combine the results of multiple, individual studies to estimate the overall magnitude of the outcome across all studies. This overall outcome is known as an effect size. To calculate the effect size for an individual study, the mean, variance estimate, and sample size are required (Rosenberg et al., 2000). Thus, although we started with 20 studies and 66 observations in the vote counting analysis and when we removed those studies that did not report descriptive statistics, did not report pre- and posttest data (or the magnitude of the change between preand posttests), or whose data were not on a scale that was comparable to the other observations in our data set, we 
Table 2. Effect size (Hedge's $g$ ) and variance for studies included in our meta-analysis of the effects of nutrition education and gardening programs on children's nutrition knowledge, preference for fruits or vegetables, and/or consumption of fruits or vegetables. These data were used to calculate the cumulative effect size $\left(E^{++}\right)$and associated statistics reported in the manuscript.

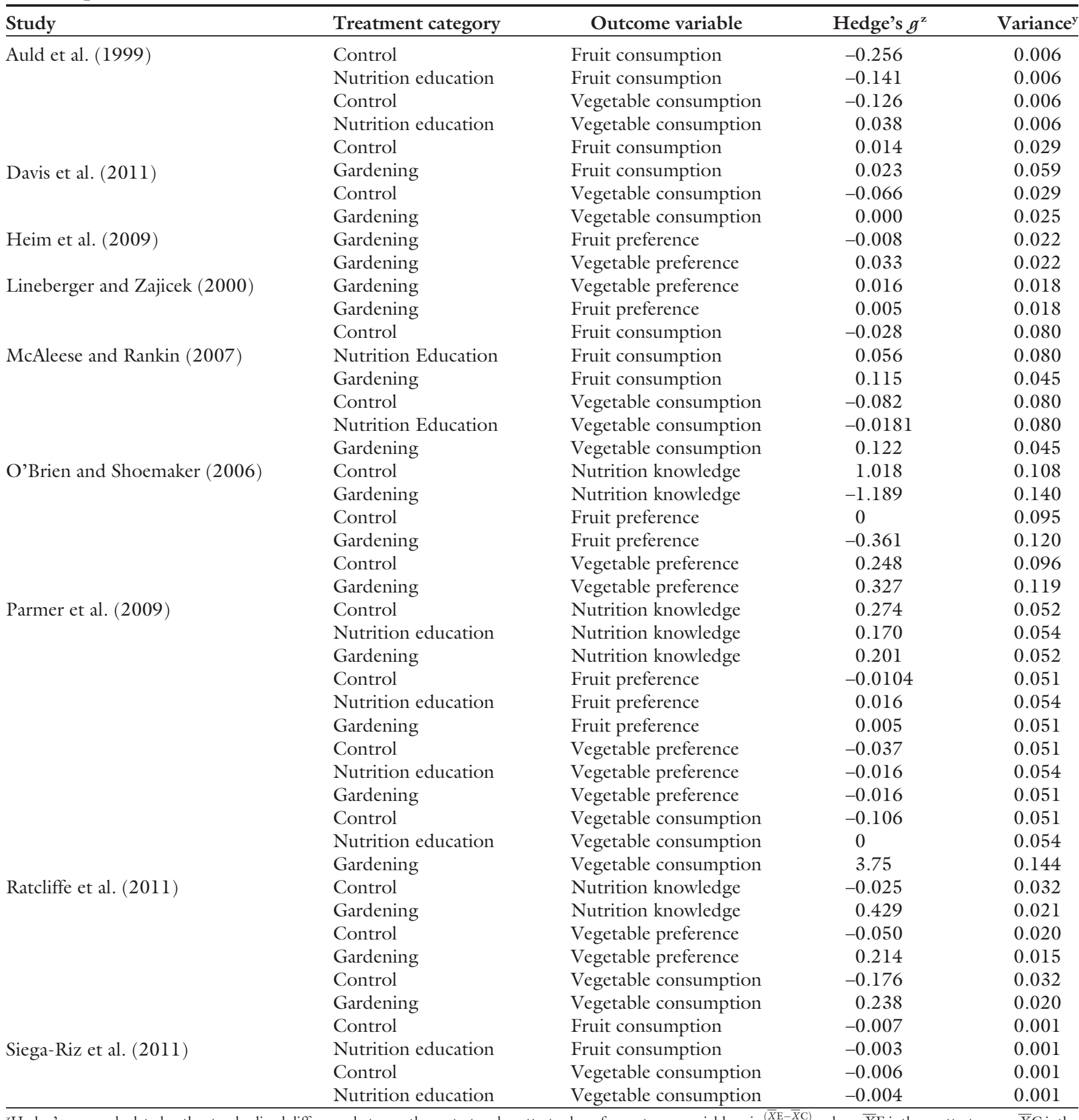

${ }^{{ }^{2} H e d g e}$ 's $g$ was calculated as the standardized difference between the pretest and posttest value of an outcome variable: $g i=\frac{(\bar{X} \mathrm{E}-\overline{\bar{D}} \mathrm{C})}{\mathrm{SD}}$, where $\bar{X} \mathrm{E}$ is the posttest mean, $\bar{X} \mathrm{C}$ is the control mean, and SD is the pooled standard deviation.

'Variances $\left(v_{g}\right)$ for each Hedge's $g$ were separately computed for each comparison: $v_{g}=\frac{N^{C}+N^{E}}{N^{C} N^{E}}+\frac{g^{2}}{2\left(N^{C}+N^{E}-2\right)}$, where $N^{C}$ and $N^{E}$ are the sample sizes of the pre- and posttest groups.

were left with only 9 studies and 46 observations (Table 2).

DatA EXTRACTION AND CAlCulation of Hedge's $g$ For each treatment category (e.g., control, nutrition education, and gardening) and each response variable (e.g., nutrition knowledge, preferences for fruit or vegetables, consumption of fruit or vegetables), means, standard deviations, and sample sizes were obtained directly from the text or tables. In cases where only the standard error was reported, the standard deviation was calculated by multiplying the standard error by $\sqrt{n}$.

As necessary, data were transformed so that all observations for a given response variable were on a common scale. For example, data for nutrition knowledge was scaled from 0 to 5 . 
Data for fruit and vegetable preferences was also scaled from 0 to 5 . In one study (Siega-Riez et al., 2011), fruit and vegetable consumption was presented in grams, rather than servings. We used the transformations presented by Morgan et al. (2010) (one serving of vegetables $=75 \mathrm{~g}$, one serving of fruit $=150 \mathrm{~g}$ ) to convert this data from grams to servings. These scales were chosen because they required the least number of data transformations (i.e., several data sets were already reported on these scales). If data could not be transformed to a common scale, it was excluded from the meta-analysis.

For each observation included in the meta-analysis, an individual effect size $\left(g_{i}\right)$ of a treatment on a response variable was estimated as the standardized mean difference between the pretest and posttest mean:

$$
g i=\frac{\left(\bar{X}_{\mathrm{E}}-\overline{\mathrm{X}}_{\mathrm{C})}\right.}{\mathrm{SD}}
$$

where $\bar{X}_{\mathrm{E}}$ is the posttest mean, $\bar{X}_{\mathrm{C}}$ is the control mean, and $\mathrm{SD}$ is the pooled standard deviation. This effect size metric, known as Hedge's g (Hedges and Olkin, 1985), was calculated using MetaWin(c) statistical software version 2.0 (Rosenberg et al., 2000). Variances $\left(v_{g}\right)$ for each Hedge's $g$ were separately computed for each comparison:

$$
v_{g}=\frac{N^{\mathrm{C}}+N^{\mathrm{E}}}{N^{\mathrm{C}} N^{\mathrm{E}}}+\frac{g^{2}}{2\left(N^{\mathrm{C}}+N^{\mathrm{E}}-2\right)},
$$

where $N^{\mathrm{C}}$ and $N^{\mathrm{E}}$ are the sample sizes of the pre- and posttest groups.

Calculating cumulative efFect Sizes AND Confidence INTERvals. To establish the effect of control, nutrition education, and gardening treatments on our response variables, we calculated cumulative effect sizes and confidence intervals (CI) (Gurevitch and Hedges, 1993; Rosenberg et al., 2000). Once again, all calculations and statistical tests were conducted using the MetaWin (C) software program (Rosenberg et al., 2000).

The cumulative effect size $\left(E^{++}\right)$ (Hedges and Olkin, 1985; Rosenberg et al., 2000) was calculated as:

$$
E^{++}=\frac{\sum_{i=1}^{n} \mathfrak{w}_{i} \mathfrak{g}_{i}}{\sum_{i=1}^{n} \mathfrak{w}_{i}},
$$

where $g_{i}$ is the effect size for the $i$ th study, and $w_{\mathrm{i}}$ is the weight (reciprocal of the sampling variance) for the $i$ th study. A positive value of $E^{++}$suggests that the treatment had a positive effect on a given response variable, whereas a negative value of $E^{++}$indicates that the treatment had a negative effect on a response variable.

Bias-corrected bootstrapped 95\% CI were calculated for each $E^{++}$ from resampling tests generated from 999 iterations (Adams et al., 1997; Rosenberg et al., 2000). When the CI did not bracket zero, $E^{++}$was considered to be significantly different from zero (Rosenberg et al., 2000).

FAIL-SAFE NUMBERS. As with most reviews, it was difficult to ensure that the sample of studies used in the analysis was representative of all studies that have been conducted. Because studies that yield significant results may be more likely to be published than those with null results, it is important to factor in the "file drawer problem" of unpublished studies (Arnqvist and Wooster, 1995). One of the strengths of meta-analysis is that it offers quantitative methods to assess the magnitude of bias against studies showing a nonsignificant effect.

To address the issue of publication bias, we generated a fail-safe number for each $E^{++}$(Rosenthal, 1979) using the MetaWin( software program (Rosenberg et al., 2000). A fail-safe number represents the number of nonsignificant studies needed in an analysis to change a significant result into a nonsignificant one. Higher the fail-safe numbers confer greater credibility to a significant result.

\section{Results}

Vote counting. For pre- vs. posttest comparisons, qualitative analysis of the vote counting results revealed that the majority of the outcomes (26 out of 39 ) were nonsignificant (Table 3). This pattern held true for the control and nutrition education groups, but not for the gardening group. In fact, the gardening group exhibited the most significant outcomes (8), with increases reported in nutrition knowledge, preference for vegetables, fruit consumption, vegetable consumption, and the combined measure of fruit and vegetable consumption.

When comparing the control group to the nutrition education group or the control group to the garden group, a total of 12 out of 27 of the outcomes were nonsignificant (Table 4 ). In the remaining 15 observations, the measured response variable was always higher in the nutrition education or gardening group, relative to the control group.

Although the gardening group showed more positive significant responses (for pre- and posttest comparisons, as well as compared with the control group) compared

Table 3. Number of observations with significant or nonsignificant outcomes in

\begin{tabular}{|c|c|c|c|c|c|c|c|c|c|}
\hline \multirow[b]{3}{*}{ Response variable } & \multicolumn{9}{|c|}{ Treatment group } \\
\hline & \multicolumn{3}{|c|}{ Control $^{\mathrm{z}}$} & \multicolumn{3}{|c|}{ Nutrition education $^{y}$} & \multicolumn{3}{|c|}{ Gardening $^{x}$} \\
\hline & $+{ }^{w}$ & $-\mathrm{v}$ & $\varnothing^{\mathrm{u}}$ & + & - & $\varnothing$ & + & - & $\varnothing$ \\
\hline Nutrition knowledge & 0 & 0 & 2 & 1 & 0 & 1 & 2 & 0 & 2 \\
\hline Fruit preference & 0 & 0 & 2 & 0 & 0 & 1 & 0 & 0 & 3 \\
\hline Vegetable preference & 0 & 0 & 2 & 0 & 0 & 2 & 2 & 0 & 2 \\
\hline $\begin{array}{l}\text { Combined fruit and } \\
\text { vegetable preference }\end{array}$ & 0 & 0 & 0 & 0 & 0 & 0 & 0 & 0 & 1 \\
\hline Fruit consumption & 0 & 1 & 1 & 0 & 0 & 2 & 1 & 0 & 0 \\
\hline Vegetable consumption & 0 & 2 & 1 & 0 & 0 & 3 & 2 & 0 & 0 \\
\hline $\begin{array}{l}\text { Combined fruit and } \\
\text { vegetable consumption }\end{array}$ & 0 & 0 & 1 & 0 & 0 & 0 & 1 & 1 & 0 \\
\hline Total & 0 & 3 & 9 & 1 & 0 & 9 & 8 & 1 & 8 \\
\hline
\end{tabular}
our vote counting analysis of pre-vs. posttest comparisons, across seven response variables and three treatment groups.

${ }^{\mathrm{z}}$ Children in a control group did not participate in a formal nutrition education or gardening program.

${ }^{y}$ Children in a nutrition education group participated in a nutrition education program that did not include a gardening component.

${ }^{\mathrm{x}}$ Children in a gardening group participated in a nutrition education program that also included a gardening component.

wPositive outcomes $(+)$ indicate that posttest values were significantly greater than pretest values, at a probability value of less than or equal to 0.05

${ }^{v}$ Negative outcomes (-) indicate that posttest values were significantly less than pretest values, at a probability value of less than or equal to 0.05 .

"Null outcomes $(\varnothing)$ indicate no significant difference between pretest and posttest values, at a probability value of less than or equal to 0.05 . 
with the other groups, the large number of nonsignificant outcomes across all treatment groups made it difficult to interpret this data with confidence.

Meta-analysis. Participation in a nutrition education program resulted in a significant increase in nutrition knowledge $\left[E^{++}=0.15, \mathrm{CI}=0.05\right.$ to $0.22, \mathrm{df}=1$, fail-safe number $=0$ (Fig. 1)]. The control group also had a significant increase in nutrition knowledge $\left[E^{++}=0.23, \mathrm{CI}=0.04\right.$ to $1.02, \mathrm{df}=2$, fail-safe number $=3.4$ (Fig. 1)]. However, the gardening treatment experienced no significant increase in nutrition knowledge $\left[E^{++}=\right.$ $0.21, \mathrm{CI}=-1.19$ to $0.43, \mathrm{df}=2$ (Fig. 1)].

The control treatment exhibited no significant changes in preferences for fruit $\left[E^{++}=-0.01, \mathrm{CI}=-0.01\right.$ to $0.00, \mathrm{df}=1$ (Fig. $2 \mathrm{~A})]$ or vegetables $\left[E^{++}=-0.01, \mathrm{CI}=-0.05\right.$ to $0.11, \mathrm{df}=2$ (Fig. 2B)]. Although the gardening treatment had no significant effect on preferences for fruit $\left[E^{++}=-0.02, \mathrm{CI}=\right.$ -0.20 to $0.01, \mathrm{df}=3$ (Fig. 2A)], it did have a significant effect on vegetable preference $\left[E^{++}=0.10, \mathrm{CI}=0.01\right.$ to $0.19, \mathrm{df}=1$, fail-safe number $=0$ (Fig. 2B)]. We did not have enough observations to quantify changes in vegetable preference or changes in fruit preference for the nutrition education treatment.

There was no significant impact of the control condition on changes in fruit consumption $[E++=-0.04$, $\mathrm{CI}=-0.24$ to $0.003, \mathrm{df}=3$ (Fig. $3 \mathrm{~A})$ ]. Unexpectedly, there was a marginally significant, negative effect of the nutrition education treatment on changes in fruit consumption $\left[E_{++}=\right.$ $-0.02, \mathrm{CI}=-0.14$ to $-0.002, \mathrm{df}=2$, fail-safe number $=0$ (Fig. 3A) $]$. The garden treatment resulted in a small, but significant increase in fruit consumption $\left[E^{++}=0.08, \mathrm{CI}=0.02\right.$ to $0.12, \mathrm{df}=1$, fail-safe number $=0$ (Fig. 3A)].

Neither the control condition $\left[E^{++}=-0.03, \mathrm{CI}=-0.14\right.$ to -0.01 , $\mathrm{df}=5$, fail-safe number $=0$ (Fig. $3 \mathrm{~B})]$ nor the nutrition education treatment $\left[E^{++}=-0.002, \mathrm{CI}=-0.0073\right.$ to 0.04 , $\mathrm{df}=2$, fail-safe number $=0$; (Fig. 3B) had a significant effect on vegetable consumption. However, students participating in a garden-based program significantly increased their vegetable consumption $\left[E^{++}=0.42, \mathrm{CI}=0.07\right.$ to $2.07, \mathrm{df}=3$, fail-safe number $=50.5$ (Fig. 3B)].

Table 4. Number of observations with significant or nonsignificant outcomes in our vote counting analysis of posttest comparisons between control and nutrition education treatments, and control vs. gardening treatments, across seven response variables.

\begin{tabular}{|c|c|c|c|c|c|c|}
\hline \multirow[b]{3}{*}{ Response variable } & \multicolumn{6}{|c|}{ Comparison } \\
\hline & \multicolumn{3}{|c|}{ Control $^{\mathrm{z}}$ vs. nutrition education ${ }^{\mathrm{y}}$} & \multicolumn{3}{|c|}{ Control vs. gardening ${ }^{x}$} \\
\hline & $+^{w}$ & $-\mathrm{v}$ & $\emptyset^{\mathrm{u}}$ & + & - & $\varnothing$ \\
\hline Nutrition knowledge & 1 & 0 & 2 & 3 & 0 & 0 \\
\hline Fruit preference & 0 & 0 & 1 & 0 & 0 & 0 \\
\hline Vegetable preference & 1 & 0 & 1 & 2 & 0 & 0 \\
\hline $\begin{array}{l}\text { Combined fruit and } \\
\text { vegetable preference }\end{array}$ & 0 & 0 & 1 & 0 & 0 & 0 \\
\hline Fruit consumption & 3 & 0 & & 0 & 0 & 1 \\
\hline Vegetable consumption & 0 & 0 & 5 & 3 & 0 & 1 \\
\hline $\begin{array}{l}\text { Combined fruit and } \\
\text { vegetable consumption }\end{array}$ & 2 & 0 & 0 & 0 & 0 & 0 \\
\hline Total & 7 & 0 & 10 & 8 & 0 & 2 \\
\hline
\end{tabular}

${ }^{2}$ Children in a control group did not participate in a formal nutrition education or gardening program.

${ }^{y}$ Children in a nutrition education group participated in a nutrition education program that did not include a gardening component.

${ }^{x}$ Children in a garden group participated in a nutrition education program that also included a gardening component. "Positive outcomes $(+)$ indicate that the nutrition education or gardening group was significantly greater than the control.

"Negative outcomes (-) indicate that the nutrition education or gardening group was significantly less than the control. "Null outcomes $(\varnothing)$ indicate no significant difference between the nutrition education or gardening group and the control.

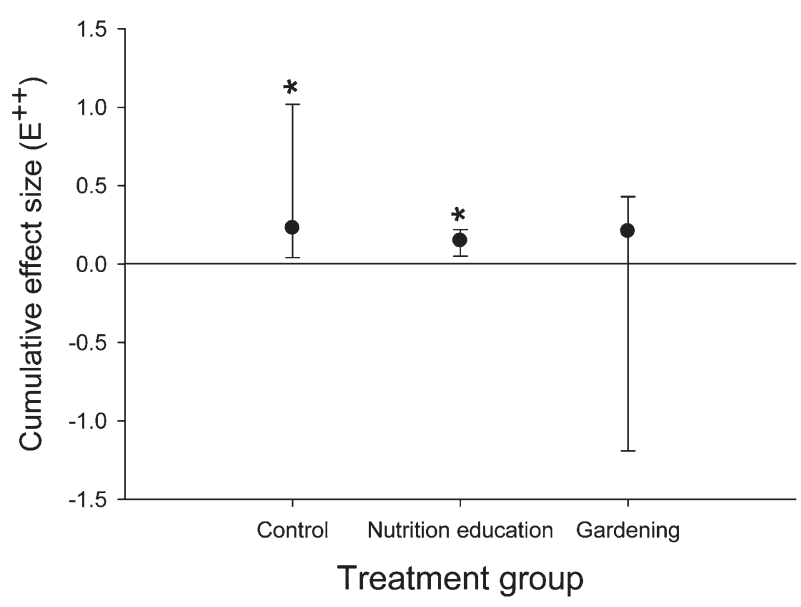

Fig. 1. Impact of control, nutrition education, and gardening treatments on changes in nutrition knowledge. Plotted points are the cumulative effect size $\left(E^{++}\right)$, and bars represent upper and lower bias-corrected bootstrapped $95 \%$ confidence intervals (CIs). $E^{++}$was calculated as: $E^{++}=\sum_{i=1}^{n}$ wigi $i / \sum_{i=1}^{n} w i$, where $g_{i}$ is the effect size for the $i$ th study, and $w_{i}$ is the weight (reciprocal of the sampling variance) for the $i$ th study. CIs were calculated for each $E^{++}$from resampling tests generated from 999 iterations. When a CI intersects the zero line, the impact of a treatment is nonsignificant. Significant outcomes are marked with an asterisk (*).

\section{Discussion}

The vote counting analysis suggested that participation in a nutrition education program leads to an increase in nutrition knowledge. However, positive attitudinal (e.g., increased preference for fruit or vegetables) and behavioral changes (e.g., increased fruit or vegetable consumption) were primarily documented in the gardening programs.
Our meta-analysis documented some interesting outcomes. However, small sample sizes (ranging from two to six observations per analysis) at times limited our ability to draw inferences from the data. Specifically, where significant outcomes were found, they were often small in magnitude and vulnerable to charges of publication bias. For example, although we documented changes in nutrition knowledge within the 

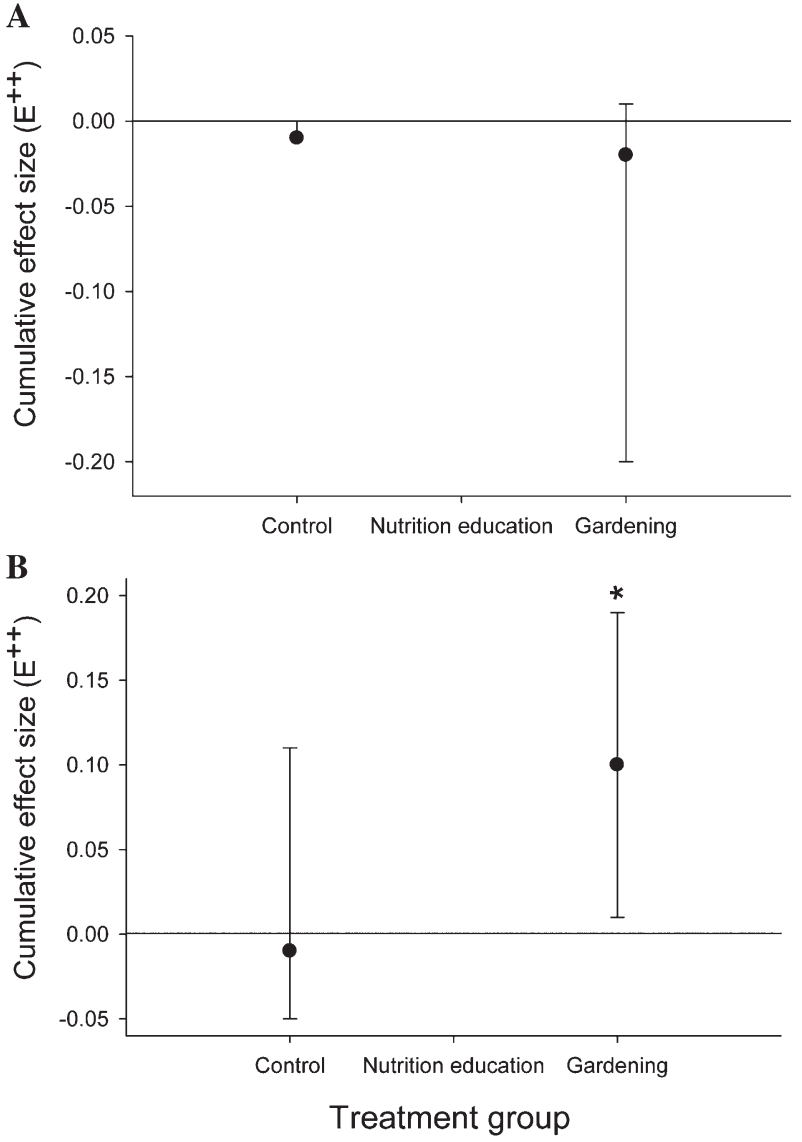

Fig. 2. Impact of control and gardening treatments on changes in preferences for (A) fruit and (B) vegetables. Sample size limitations precluded an analysis of the impact of the nutrition education treatment on preferences for fruit or vegetables. Plotted points are the cumulative effect size $\left(E^{++}\right)$, and bars represent upper and lower bias-corrected bootstrapped $95 \%$ confidence intervals (CIs). $E^{++}$was calculated as: $E^{++}=\sum_{i=1}^{n} w i g i / \sum_{i=1}^{n} w i$, where $g_{i}$ is the effect size for the $i$ th study, and $w_{i}$ is the weight (reciprocal of the sampling variance) for the $i$ th study. CIs were calculated for each $E_{++}$from resampling tests generated from 999 iterations. When a CI intersects the zero line, the impact of a treatment is nonsignificant. Significant outcomes are marked with an asterisk (*).

nutrition education treatment, the small effect size $\left(E^{++}=0.15\right)$ and small fail-safe number $(0)$ suggests that this result should be interpreted with a degree of skepticism. We also documented a significant change in nutrition knowledge in the control group. The effect size for this pre- vs. posttest comparison was higher in magnitude $\left(E^{++}=0.23\right)$ and of greater credibility (fail-safe number $=3.4$ ) compared to the result for the nutrition education group. Together, these results suggest that our meta-analysis of changes in nutrition knowledge may have been influenced by publication bias toward studies that report significant results and/or developmental changes in children's nutrition knowledge, over time.

Similarly, the small effect sizes and low fail-safe numbers associated with the impact of gardening on preferences for vegetables $\left[E^{++}=\right.$ 0.10 , fail-safe number $=0$ (Fig. 2B)] and consumption of fruit $\left[E^{++}=0.08\right.$, fail-safe number $=0$ (Fig. 3A) $]$ suggest that these results should also be interpreted with caution. More data are needed to confidently assert that gardening programs increase preferences for vegetables and/or consumption of fruit.

To promote improved and more robust meta-analyses in the future, we encourage school garden researchers to report means, sample sizes, and measures of variance. In addition, we encourage researchers to report results using the common currency of servings of fruit and servings of vegetables. One especially well-designed and executed study (Gortmaker et al., 1999) reported a combined measure of servings of fruit and vegetables.
However, since it was the only study to report servings of fruit and vegetables, combined, we excluded it from our analysis since the data were not comparable to the larger data set.

In several regards, the result of the gardening treatment on vegetable consumption is the most robust result to come out of this meta-analysis. First, the effect size associated with the effect of gardening programs on vegetable consumption $\left(E^{++}=0.42\right)$ can be classified as a moderate effect (Cohen, 1962). In addition, the large fail-safe number (50.5) suggests that more than 50 additional, nonsignificant studies would have to be added to this data set to change the impact of gardening on vegetable consumption from significant to nonsignificant. By comparison, there were no significant, positive changes in fruit or vegetable consumption for the nutrition education treatment. Because participation in a garden-based educational program increases consumption of vegetables, public health and nutrition education programs would benefit from including gardening as a featured component of wellness programs and policies.

Although most of the studies did not detail what they grew in their gardens, it is reasonable to assume that the focus was on growing vegetables, rather than on fruit (in this context, we are referring to culinary fruit and not botanical fruit). Thus, it is not surprising that the most robust result of this study was the increase in vegetable consumption in children participating in a gardening program. This group's increase in fruit consumption, by comparison, was smaller.

We suggest two nonmutually exclusive hypotheses that might explain why gardening might promote greater vegetable consumption in children. First, gardening provides children with increased access to vegetables, and this increased access may result in greater consumption. Second, gardening can decrease a child's hesitance to try new foods by exposing children to a broad array of garden-grown vegetables. A study conducted by Birch et al. (1987) found that it takes between 10 and 15 exposures to a new food before a child will accept this new food into their diet. Of these 10-15 exposures, at least one has to be a taste. However, seeing, touching, planting, growing, and harvesting food are powerful and positive ways to expose children to vegetables or 

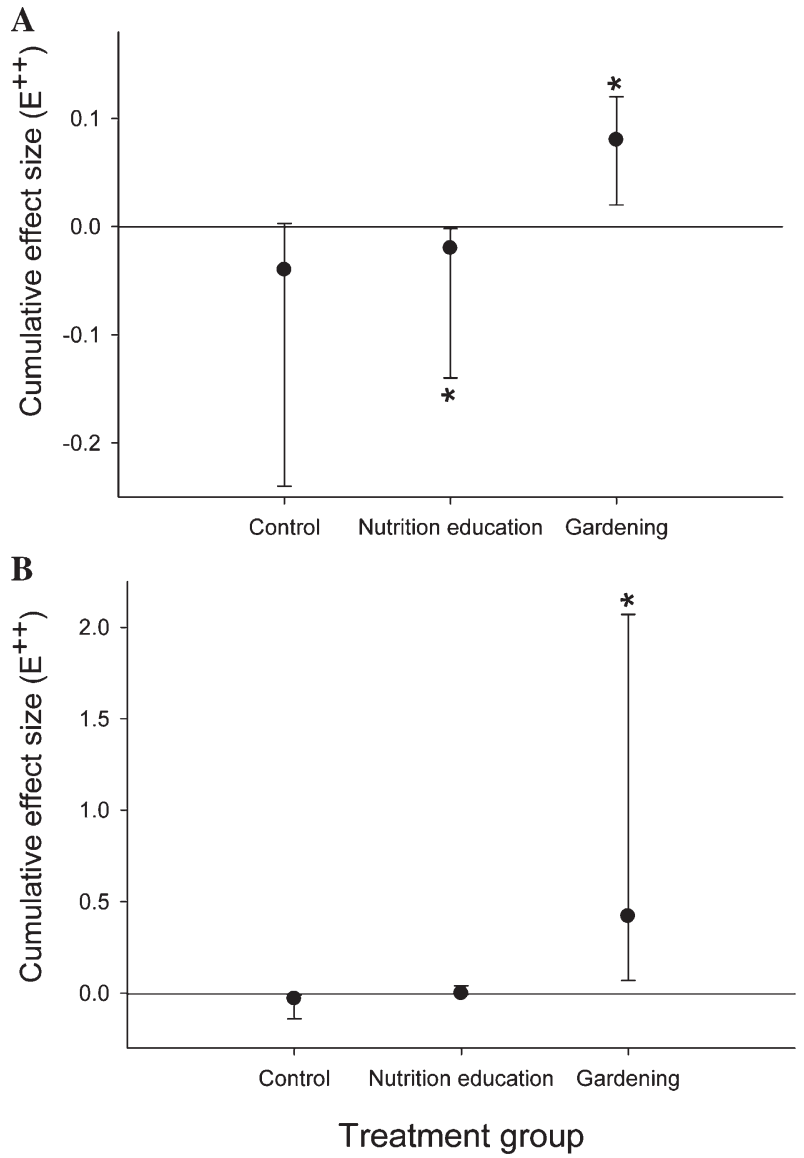

Fig. 3. Impact of control, nutrition education, and gardening treatments on changes in consumption of $(A)$ fruit and $(B)$ vegetables. Plotted points are the cumulative effect size $\left(E^{++}\right)$, and bars represent upper and lower bias-corrected bootstrapped $95 \%$ confidence intervals (CIs). $E^{++}$was calculated as: $E^{++}=\sum_{i=1}^{n} w i g i / \sum_{i=1}^{n} w i$, where $g_{i}$ is the effect size for the $i$ th study, and $w_{i}$ is the weight (reciprocal of the sampling variance) for the $i$ th study. CIs were calculated for each $E_{++}$from resampling tests generated from 999 iterations. When a CI intersects the zero line, the impact of a treatment is nonsignificant. Significant outcomes are marked with an asterisk (*).

fruit that they may not have had much experience with in the past. Coupled with the greater access to garden-grown vegetables, the mere act of gardening has the potential to both encourage and provide for vegetable consumption.

Based upon the results of this meta-analysis, where we found that gardening has a greater impact on vegetable consumption than other nutrition education programs, we advocate for greater funding for rigorous research of the social, behavioral, and academic impacts of school gardens on children. Garden programs have a history of being chronically underfunded (Graham et al., 2005; Phibbs and Relf, 2005). This lack of funding has impeded both the broader adoption of school gardens and research on the potential social, behavioral, and academic impacts of gardening on children (Phibbs and
Relf, 2005). Relatively few school garden studies have been supported by national grants. This makes it difficult to recruit, study, and track participants in a rigorous experimental study.

Another challenge to nutrition educators and school garden advocates has been working within the guidance of the Supplemental Nutrition Assistance Program Education (SNAP-Ed) program. SNAP-Ed is arguably the most ubiquitous program focused on obesity prevention, with a goal to increase the likelihood that low-income individuals, families, and children "will make healthy food choices within a limited budget" [U.S. Department of Agriculture (USDA), 2011]. However, current and historical guidance disallows the use of SNAP-Ed funds to pay for the basic tools and supplies needed to start or maintain a garden (USDA,
2011). Thankfully, the guidance for 2013 has been revised to allow for "the purchase of seeds, plants, and small gardening tools and supplies to assist in developing school and community gardening projects" (USDA, 2012).

In addition to the upcoming changes in SNAP-Ed guidance, other positive signs for the school garden movement include the relatively recent funding of the Delta Garden Study and the People's Garden Project. We hope that national support for garden-based educational programs and research will continue and grow, and suggest that researchers refer to the work of Phibbs and Relf (2005) for a list of common problems encountered in garden-based research projects, as well as suggestions for improving research on youth garden projects.

\section{Literature cited}

Adams, D.C., J. Gurevitch, and M.S. Rosenberg. 1997. Resampling tests for meta-analysis of ecological data. Ecology 78:1277-1283.

Arnqvist, G. and D. Wooster. 1995. Meta-analysis: Synthesizing research findings in ecology and evolution. Trends Ecol. Evol. 10:236-240.

Auld, G.W, C. Romaniello, J. Heimendinger, C. Hambidge, and M. Hambidge. 1999. Outcomes from a school-based nutrition education program alternating special resource teachers and classroom teachers. J. School Health 69:403-408.

Baranowski, T., M. Davis, K. Resnicow, J. Baranowski, C. Doyle, L.S. Lin, M. Smith, and D.T. Wang. 2000. Gimme 5 fruit, juice, and vegetables for fun and health: Outcome evaluation. Health Educ. Behav. 27:96-111.

Birch, L.L., L. McPhee, B.C. Shoba, E. Pirok, and L. Steinberg. 1987. What kind of exposure reduces children's food neophobia? Looking vs. tasting. Appetite 9:171-178.

Cohen, J. 1962. The statistical power of abnormal-social psychological research: A review. J. Abnorm. Soc. Psychol. 65:145-153.

Cooke, L. 2007. The importance of exposure for healthy eating in childhood: A review. J. Hum. Nutr. Diet. 20:294-301.

Davis, J.N., E.E. Ventura, L.T. Cook, L.E. Gyllenhammer, and N.M. Gatto. 2011. LA Sprouts: A gardening, nutrition, and cooking intervention for Latino youth improves diet and reduces obesity. J. Amer. Dietetic Assn. 111:1223-1230.

Delgado-Noguera, M., S. Tort, M.J. Martínez-Zapata, and X. Bonfill. 2011. 
Primary school interventions to promote fruit and vegetable consumption: A systematic review and meta-analysis. Prev. Med. 53:3-9.

Dietz, W.H. 1998. Childhood weight affects adult morbidity and mortality. J. Nutr. 128:411S-414S.

Ebbeling, C.B., D.B. Pawlak, and D.S. Ludwig. 2002. Childhood obesity: Public health crisis, common sense cure. Lancet 360:473-481.

French, S.A. and G. Stables. 2003. Environmental interventions to promote vegetable and fruit consumption among youth in school settings. Prev. Med. 37:593-610.

Gortmaker, S.L., K. Peterson, J. Wiecha, A.M. Sobol, S. Dixit, M.K. Fox, and N. Laird. 1999. Reducing obesity via a school-based interdisciplinary intervention among youth: Planet Health. Arch. Pediatr. Adolesc. Med. 153:409-418.

Graham, H., D.L. Beall, M. Lussier, P. McLaughlin, and S. ZidenbergCherr. 2005. Use of school gardens in academic instruction. J. Nutr. Educ. Behav. 37:147-151.

Graham, H. and S. Zidenberg-Cherr. 2005. California teachers perceive school gardens as an effective nutritional tool to promote healthful eating habits. J. Amer. Dietetic Assn. 105:1797-1800.

Gurevitch, J. and L.V. Hedges. 1993. Meta-analysis: Combining the results of independent experiments, p. 378-398. In: S.M. Scheiner and J. Gurevitch (eds.). Design and analysis of ecological experiments. Chapman Hall, New York.

Hedges, L.V. and I. Olkin. 1985. Statistical methods for meta-analysis. Academic Press, San Diego, CA.

Heim, S., J. Stang, and M. Ireland. 2009. A garden pilot project enhances fruit and vegetable consumption among children. J. Amer. Dietetic Assn. 109:1220-1226.

Hermann, J.R., S.P. Parker, B.J. Brown, Y.J. Siewe, B.A. Denney, and S.J. Walker. 2006. After-school gardening improves children's reported vegetable intake and physical activity. J. Nutr. Educ. Behav. 38:201-202.

Koch, S., T.M. Waliczek, and J.M. Zajicek. 2006. The effect of a summer garden program on the nutritional knowledge, attitudes, and behaviors of children. HortTechnology 16:620-625.

Lineberger, S.E. and J.M. Zajicek. 2000. Can a hands-on teaching tool affect student's attitudes and behaviors regarding fruit and vegetables? HortTechnology 10:593-597.

McAleese, J.D. and L.L. Rankin. 2007. Garden-based nutrition education affects fruit and vegetable consumption in sixth- grade adolescents. J. Amer. Dietetic Assn. 107:662-665.

Morgan, P.J., J.M. Warren, D.R. Lubans, K. Saunders, G. Quick, and C.E. Collins. 2010. The impact of nutrition education with and without a school garden on knowledge, vegetable intake and preferences and quality of school life among primary school students. Public Health Nutr. 13:1931-1940.

Morris, J.L., A. Neustadter, and S. ZidenbergCherr. 2001. First-grade gardeners more likely to taste vegetables. Calif. Agr. 55:43-46.

Morris, J.L., M. Briggs, and S. ZidenbergCherr. 2002. Development and evaluation of a garden-enhanced nutrition education curriculum for elementary school children. J. Child Nutr. Mgt. Issue 2. 22 Mar. 2012. <http://docs.schoolnutrition. org/newsroom/jcnm/02fall/morris/>.

O'Brien, S.A. and C.A. Shoemaker. 2006. An after-school gardening club to promote fruit and vegetable consumption among fourth grade students: The assessment of social cognitive theory constructs. HortTechnology 16:24-29.

Ogden, C. and M. Carroll. 2010. National Center for Health Statistics. Prevalence of obesity among children and adolescents: United States, trends 1963-1965 through 2007-2008. 12 June 2012. <http:// www.cdc.gov/nchs/data/hestat/obesity_ child_07_08/obesity_child_07_08.htm>.

Parmer, S.M., J. Salisbury-Glennon, D. Shannon, and B. Struempler. 2009. School gardens: An experiential learning approach for a nutrition education program to increase fruit and vegetable knowledge, preference, and consumption among second-grade students. J. Nutr. Educ. Behav. 41:212-217.

Perry, C.L., D.B. Bishop, G. Taylor, D.M. Murray, R. Warren Mays, B.S. Dudovitz, M. Smyth, and M. Story. 1998. Changing fruit and vegetable consumption among children: The 5-a-Day Power Plus Program in St. Paul, Minnesota. Amer. J. Public Health 88:603-609.

Perry, C.L., D.B. Bishop, G.L. Taylor, M. Davis, M. Story, C. Gray, S.C. Bishop, R.A. Warren Mays, L.A. Lytle, and L. Harnack. 2004. A randomized school trial of environmental strategies to encourage fruit and vegetable consumption among children. Health Educ. Behav. 31:65-76.

Phibbs, E.J. and D. Relf. 2005. Improving research on youth gardening. HortTechnology 15:425-428.

Pollan, M. 2008. Farmer in Chief. New York Times Mag. 7 Dec. 2011. <http://www.nytimes.com/2008/10/ 12/magazine/12policy-t.html>.
Poston, S.A., C.A. Shoemaker, and D.A. Dzewaltowski. 2005. A comparison of a gardening and nutrition program with a standard nutrition program in an out-of-school setting. HortTechnology 15:463-467.

Ratcliffe, M.M., K.A. Merrigan, B.L. Rogers, and J.P. Goldberg. 2011. The effects of school garden experiences on middle schoolaged students' knowledge, attitudes, and behaviors associated with vegetable consumption. Health Promot. Pract. 12:36-43.

Reynolds, K.D., F.A. Franklin, D. Binkley, J.M. Raczynski, K.F. Harrington, K.A. Kirk, and S. Person. 2000. Increasing the fruit and vegetable consumption of fourthgraders: Results from the High 5 Project. Prev. Med. 30:309-319.

Robinson-O'Brien, R., M. Story, and S. Heim. 2009. Impact of garden-based youth nutrition intervention programs: A review. J. Amer. Dietetic Assn. 109:273-280.

Rosenberg, M.S., D.C. Adams, and J. Gurevitch. 2000. MetaWin: Statistical software for meta-analysis with resampling tests, ver. 2.0. Sinauer Assoc., Sunderland, MA.

Rosenthal, R. 1979. The file drawer problem and tolerance for null results. Psychol. Bull. 86:638-641.

Siega-Riz, A.M., L.E. Ghormil, C. Mobley, B. Gillis, D. Stadler, J. Hartstein, S.L. Volpe, A. Virus, and J. Bridgman, and the HEALTHY Study Group. 2011. The effects of the HEALTHY study intervention on middle school student dietary intakes. Intl. J. Behavioral Nutr. Phys. Activity 8:7. 22 Mar. 2012. <http:// www.ijbnpa.org/content/8/1/7>.

Stice, E., H. Shaw, and C.N. Marti. 2006. A meta-analytic review of obesity prevention programs for children and adolescents: The skinny on interventions that work. Ecol. Bull. 132:667-691.

U.S. Department of Agriculture. 2011. Supplemental Nutrition Assistance Program education: SNAP-Ed plan guidance, Fiscal Year 2012. 22 Mar. 2012. <www.nal.usda.gov/fsn/Guidance/ FY2012SNAP-EdGuidance.pdf $>$.

U.S. Department of Agriculture. 2012. Supplemental Nutrition Assistance Program education: SNAP-Ed plan guidance, Fiscal Year 2013. 2 May 2012. <www.nal.usda.gov/fsn/Guidance/ FY2013SNAP-EdPlanGuidance.pdf>.

Wright, W. and L. Rowell. 2010. Examining the effect of gardening on vegetable consumption among youth in kindergarten through fifth grade. Wis. Med. J. 109:125-129. 